\title{
Expected I nflation, Expected Stock Returns, and Money Illusion: What can we learn from Survey Expectations?
}

Maik Schmeling* Andreas Schrimpf**

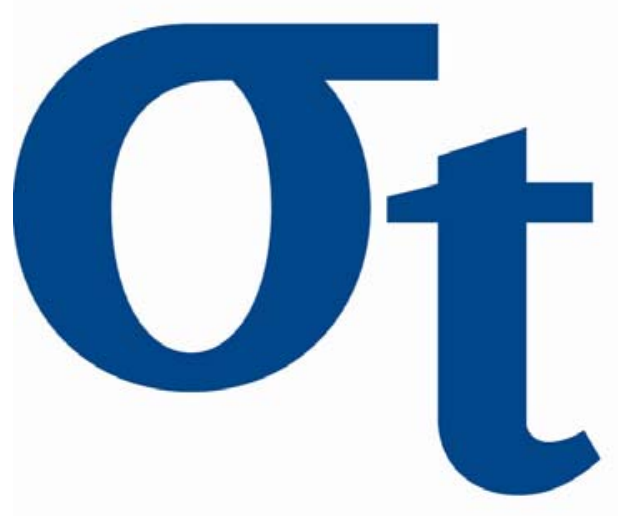

* Leibniz Universität Hannover, Germany

** Centre for European Economic Research Mannheim, Germany

This research was supported by the Deutsche Forschungsgemeinschaft through the SFB 649 "Economic Risk". 


\title{
Expected Inflation, Expected Stock Returns, and Money Illusion: What can we learn from Survey Expectations?*
}

\author{
Maik Schmeling ${ }^{\dagger} \quad$ Andreas Schrimpf ${ }^{\ddagger}$
}

This draft: May 7, 2008

\begin{abstract}
We show empirically that survey-based measures of expected inflation are significant and strong predictors of future aggregate stock returns in several industrialized countries both in-sample and out-of-sample. By empirically discriminating between competing sources of this return predictability by virtue of a comprehensive set of expectations data, we find that money illusion seems to be the driving force behind our results. Another popular hypothesis - inflation as a proxy for aggregate risk aversion - is not supported by the data.
\end{abstract}

JEL-Classification: G10, G12, E44

Keywords: Inflation expectations, Money Illusion, Proxy hypothesis, Stock returns

*The authors want to thank Deutsche Forschungsgemeinschaft (DFG) through SFB 649 "Economic Risk" at Humboldt University (Berlin) and the Centre for European Economic Research (ZEW, Mannheim) for financial and data suport.

$\dagger$ Maik Schmeling, Department of Economics, Leibniz Universität Hannover, Königsworther Platz 1, 30167 Hannover, Germany, email: schmeling@gif.uni-hannover.de, phone: +49 511 7628213.

$¥$ Andreas Schrimpf, Centre for European Economic Research (ZEW) Mannheim, P.O. Box 10 34 43, 68034 Mannheim, Germany, email: schrimpf@zew.de, phone: +49 6211235160. 


\section{Introduction}

It is empirically well documented that the correlation of inflation and stock returns is negative or non-existent (Fama and Schwert, 1977; Fama, 1981; Amihud, 1996). This puzzling piece of evidence stands in sharp contrast to widely accepted economic principles, such as Fisher Parity, and gives rise to the impression that something seems "wrong" with inflation and the stock market. However, the stock returninflation relationship is of crucial importance, since it quantifies the degree to which equities are a hedge against inflation risk. Furthermore, central banks aiming at targeting inflation or controlling inflation expectations have to take into account spillovers from inflation to asset returns, which again feed back into real economic activity (see e.g. Barro, 1990; Stock and Watson, 2003).

We contribute to the strand of literature that analyzes the relation of inflation and stock returns by examining genuine expectation data on inflation for several industrialized countries. This seems to represent a novel approach for the literature and produces some fresh insights into the relation of expected inflation and equity returns which have not been shown before. Our main results are, first, that expected inflation does indeed strongly and positively forecast stock returns in- and out-of-sample for several industrialized countries. Second, we discriminate between competing economic rationales for this predictive power and find that the relationship seems to stem from money illusion (Modigliani and Cohn, 1979; Cohen, Polk, and Vuolteenaho, 2005) rather than inflation being a proxy for an omitted macro factor (Fama, 1981) or risk aversion (Brandt and Wang, 2003). Finally, our paper also contributes towards a better understanding of the role that monetary factors play for stock markets - a topic which has been largely neglected in earlier papers (Cochrane, 2007, p.76).

Despite the early evidence on an anomalous relation between inflation and asset returns, there is good reason to believe that expected inflation should be positively related to future stock returns, both in nominal and real terms. ${ }^{1}$ First, under investor

\footnotetext{
${ }^{1}$ We stress that our findings relate to expected inflation and stock returns. Therefore, our results do not corroborate or refute many earlier studies that focus on actual or unexpected inflation.
} 
rationality, expected inflation is often considered as being positively correlated with some unobserved macro variable or risk aversion (Fama, 1981; Brandt and Wang, 2003) in such a way that higher inflation expectations are associated with a higher equity premium and thus, expected stock returns. A second - but behavioral channel through which inflation might affect stock returns is money illusion (Fisher, 1928). Modigliani and Cohn (1979) argue that investors discount real stock cash flows with nominal discount factors, thereby undervaluing equities in times of high inflation and vice versa. Since this undervaluation will be eliminated once actual cash flows are revealed, high inflation today will forecast subsequent price increases and will generate a positive relation between inflation and expected stock returns. Despite the fact that stakes are high in the stock market so that money illusion should quickly be arbitraged away, several papers show that even a small amount of money illusion in the market is sufficient to generate large effects (Fehr and Tyran, 2001; Basak and Yan, 2005). Likewise, the leading practitioner model of equity valuation, the so-called "Fed model", falls prey to the "pedestrian mistake" of money illusion but seems to be widely used by professional investors (Cohen, Polk, and Vuolteenaho, 2005, p. 641). ${ }^{2}$ Therefore, money illusion may be expected to be an important factor in determining the time variation of aggregate stock market returns.

A crucial ingredient for an analysis of expected inflation and asset returns is the choice of a proxy for expected inflation. ${ }^{3}$ We choose a new route to investigate this seemingly anomalous relation and rely on proxies for near-term expected inflation derived from a comprehensive survey of professional forecasters covering the U.S., U.K., Germany, France, Italy, and Japan, which allows an international investigation of inflation and asset returns. Up to now, the use of survey data is still relatively unexplored in the literature and allows us to circumvent joint hypotheses problems

\footnotetext{
${ }^{2}$ The Fed model is based on the presumption that stocks and bonds are "competing" assets and that equity earnings yields follow bond yields in the long run.

${ }^{3}$ Earlier papers employed different approaches to proxy for expected or unexpected inflation, including e.g. measures derived from short-term interest rates (Fama and Schwert, 1977), timeseries methods (e.g. Gultekin, 1983), macro news announcements (Flannery and Protopapadakis, 2002), projections of actual inflation rates on instrumental variables considered to predict inflation (e.g. Pilotte, 2003), past and current realized inflation rates (Barnes, Boyd, and Smith, 1999) and survey data on very long-term inflation expectations (Sharpe, 2002).
} 
induced by imposing models when determining inflation expectations.

By utilizing the richness of the expectation data, we first document that expected inflation significantly forecasts stock returns in- and out-of-sample, even when controlling for other factors, such as expectations about output movements, lagged dividend yields, and lagged term spreads. To the best of our knowledge, this positive forecasting relation has not been shown before. ${ }^{4}$ We then move on to discriminate between competing hypotheses to explain this predictive power. We make use of subjective investor expectations about future stock returns, output movements, and inflation movements to investigate whether the rational (proxy hypothesis, risk aversion) or behavioral (money illusion) view is a more likely candidate to explain the positive correlation between expected inflation and expected stock returns. We find that subjective expectations about stock returns are negatively affected by inflation expectations - a result that sharply contradicts the risk aversion explanation. However, as we will argue below, this finding is well in line with money illusion.

The rest of the paper is structured as follows. The next section details competing hypotheses about the relation between inflation and expected stock returns and describes our approach to make a distinction between these competing hypotheses. Section 3 details our data and provides descriptive statistics, section 4 discusses the econometric approach and reports forecasting regression results, section 5 discriminates between competing hypotheses. Finally, section 6 concludes.

\section{Competing Hypotheses}

This section discusses possible explanations for the predictive power of expected inflation for future stock returns. To get a better grasp of ideas, we use a standard consumption-based asset pricing framework as the conceptual starting point. Specifically, the CCAPM with CRRA utility over consumption $\mathcal{U}\left(c_{t}\right)=c_{t}^{1-\gamma} /(1-\gamma)$ implies the basic asset pricing equation

\footnotetext{
${ }^{4}$ Campbell and Vuolteenaho (2004) and Boucher (2006) also investigate forecasts based on inflation but not for stock returns per se.
} 


$$
\mathbb{E}_{t}\left[\delta\left(c_{t+1} / c_{t}\right)^{-\gamma} R_{t+1}\right]=1
$$

where $R$ denotes a (real) gross return, $c_{t}$ denotes real consumption at time t, $\delta$ is the subjective time discount factor, and $\gamma$ denotes the risk aversion coefficient (see e.g. Cochrane, 2005). This is the classic workhorse of cross-sectional macro-finance asset pricing and it has a simple interpretation. The conditional expectation of the gross return of any asset, discounted by the stochastic discount factor (which equals the marginal rate of intertemporal subsitition, $M_{t+1}=\delta\left(c_{t+1} / c_{t}\right)^{-\gamma}$, in our context) is equal to one. However, this basic relation may also simply be reinterpreted to yield the time-series implications for asset prices that we are interested in. In order to do so, it is necessary to perform a covariance decomposition of (1) above, then take logs (and ignore Jensen's inequality terms for simplicity), and rearrange the resulting expression to obtain

$$
\mathbb{E}_{t}\left[r_{t+1}\right] \approx \phi+\gamma \mathbb{E}_{t}\left[\triangle c_{t+1}\right]
$$

where $r$ now denotes the asset's real log return, $\gamma$ denotes agents' risk aversion, and $\phi$ is a function of the conditional covariance of log consumption growth $\triangle c_{t+1}$ and the log return which we assume to be constant. The conditional covariance of consumption growth and returns is a key ingredient of cross-sectional asset pricing, but rather uninteresting for our purpose here since we are interested in the time-series implications of the basic pricing equation. Therefore, we focus our interest on the remaining two parts of (2). As the approximate relationship in (2) shows, expected returns are higher when aggregate risk aversion $\gamma$ is high and when consumption growth is expected to be high. While there is no room for expected inflation to directly impact real returns in this framework, the literature has identified ways of how inflation may have an indirect influence on (2).

In an early contribution, Fama (1981) advanced the so-called "proxy hypothesis", which states that inflation proxies for an unobservable or merely unidentified real macroeconomic variable driving fundamental stock values. Thus, in the context 
of (2), expected inflation may contain information about future returns, as long as it proxies for some macro variable driving business conditions and consumption growth. ${ }^{5}$ A somewhat related explanation, which we will subordinate under the proxy hypothesis, is that agents are anxious about inflation and that bad news about inflation induces higher aggregate risk aversion (see e.g. Campbell and Vuolteenaho, 2004). Here, expected inflation proxies for risk aversion, and Shiller (1996) documents this sort of anxiety on behalf of U.S. consumers. Earlier papers have indeed incorporated this idea into asset pricing models (see Brandt and Wang (2003) for an application). Under this framework, higher inflation expectations lead to an increase in $\gamma$ in (2), which in turn implies higher expected returns.

Money illusion generally makes identical predictions about the forecasting power of inflation for asset returns. Most prominently, Modigliani and Cohn (1979) suggest that agents suffer from money illusion in the sense that they discount real cash flows with nominal discount rates. Under this hypothesis, an overly strong (weak) nominal discounting of future real cash flows in times of higher (lower) inflation expectations depresses (raises) current stock prices and thus leads to an undervaluation (overvaluation) of equity markets. Again, this result may be illustrated using Equation (2). If investors suffer from money illusion, they will use a nominal discount rate and the Equation (2) will now read

$$
\mathbb{E}_{t}\left[r_{t+1}\right] \approx \phi+\gamma \mathbb{E}_{t}\left[\triangle C_{t+1}\right]=\phi+\gamma \mathbb{E}_{t}\left[\triangle c_{t+1}+\pi_{t+1}\right]
$$

where $C$ denotes nominal consumption and $\pi$ denotes inflation. ${ }^{6}$ Therefore, under money illusion, higher inflation expectations imply higher stock returns in the future. Where does this return predictability stem from? Let us take, for example, increasing expectations concerning the future path of inflation. A money-illusioned investor will tend to discount in an overly strong manner, thereby undervaluing

\footnotetext{
${ }^{5}$ It should be noted, however, that Fama (1981) constructs a negative relation between inflation and returns. However, the proxy hypothesis more generally describes an omitted variable problem that may have different effects on the relation between inflation and stock returns.

${ }^{6}$ The analogy between consumption growth and the discount factor is most obvious in the context of the CCAPM.
} 
assets in the current period. This undervaluation induced by money illusion will be eliminated over time when actual cash flows become known and prices return to (higher) rational levels (see e.g. Brunnermeier and Juillard, 2007). Therefore, higher inflation expectations imply higher returns in the future.

Both, the hypothesis of inflation as a proxy for some underlying macroeconomic variable or driver of risk aversion, and the Modigliani-Cohn hypothesis predict that expected inflation should contain information about future returns. This prediction can easily be verified by estimating forecasting regressions to test for such predictive power. However, distinguishing between rational (proxy hypothesis, risk aversion) and behavioral (money illusion) explanations is a difficult task as noted by Campbell and Vuolteenaho (2004). No econometric analysis will be able to control for all possible omitted variables that expected inflation might proxy for, which makes it difficult to separate the two channels. Therefore, Cohen, Polk, and Vuolteenaho (2005) conclude that earlier tests for the aggregate effects of money illusion cannot be seen as very compelling. While these authors derive a joint test of money illusion and the CAPM, which provides valuable insights, we propose a complementary model-free test that does not assume a particular asset pricing model and thus does not rely on a joint hypothesis.

Specifically, we examine the relation among subjective expectations concerning output, inflation and stock returns to construct a direct test of a rational versus an irrational explanation. Under the null of investor rationality and the proxy hypothesis, expected inflation proxies for expected output movements and/or a factor that drives aggregate risk aversion. Under this specification, subjective return expectations should be driven by subjective expectations about output and, in case of an omitted variable problem, they should be positively correlated with subjective inflation expectations. Using such subjective investor expectations on inflation and returns is a convenient way to circumvent the problem posed by omitted variables. Since subjective return forecasts already include effects from all variables unobservable by the econometrician, one may test whether expected inflation proxies for such an omitted variable. 
Conversely, under pure money illusion and no correlation of inflation with aggregate risk aversion, subjective return expectations must be largely uncorrelated or may even be negatively correlated with inflation expectations. The latter follows from the logic that illusion is part of the story. Being illusioned means that investors do not recognize their error and the resulting misvaluation (i.e. people must be assuming that adjusting the nominal discount factor to inflation expectations is the end of the story). For example, higher inflation expectations will lead to a decrease in stock prices but should have no effect on subjective return expectations since inflation per se does not change aggregate risk exposure under money illusion. Therefore, subjective expectations about returns and inflation should not be positively related. However, if inflation increases or decreases over a prolonged period of time as empirical evidence strongly suggests (e.g. Gali, Gertler, and Lopez-Salido, 2001), subjective return expectations may even be negatively correlated with inflation under money illusion.

Based on these arguments, we test for a rational (proxy hypothesis) versus behavioral (money illusion) explanation for the predictive content of expected inflation for future returns by directly investigating subjective macroeconomic and return expectations. Based on a comprehensive set of investor expectations, this approach exempts us from making additional assumptions on returns or agents' behavior.

\section{$3 \quad$ Data and Descriptive Statistics}

This section provides basic descriptive statistics and discusses the usefulness of the primary data on inflation expectations employed in the empirical analysis below.

For an analysis like ours, the data bottleneck is a proxy for expected inflation. As described in the preceding sections, researchers have creatively sought for such proxies. However, little evidence is based on genuine investor expectations for relevant time horizons. We employ six months inflation expectations which are obtained from a monthly survey of professional forecasters. The survey is conducted by the Centre for European Economic Research (ZEW), one of Germany's largest economic 
research institutes. The survey results usually receive substantial attention from the financial community, and the data are well-known from earlier academic studies (see e.g. the discussion in Pesaran and Weale, 2006). Our data covers a time span from December 1991 (when the survey was started) to September 2007 which yields a total of 190 monthly observations.

The monthly survey asks about 350 respondents (professional analysts, treasurers, economists etc. at leading banks, insurance and industrial companies in Germany) for their opinion about several key macro variables, including CPI inflation for Germany, the U.S., the U.K., France, Italy, and Japan. Answers to this question can be "up", "unchanged", "down", and "no opinion". Therefore, we are dealing with qualitative survey data and our proxy for expected inflation measures whether inflation is expected to increase or decrease (disinflation) and does not measure whether forecasters expect inflation, no inflation or deflation. Survey measures of inflation have been widely used in different contexts (e.g. Giordani and Soederlind, 2003) and have been shown to be very informative for future inflation (Ang, Bekaert, and Wei, 2007). In the following, we will use the terms inflation expectations, expected inflation, and inflation sentiment interchangeably.

We aggregate expected inflation answers across forecasters by subtracting the share of forecasters who vote "down" from the share of forecasters who vote "up". This yields an aggregate measure of expected inflation, a so-called balance statistic, which varies between -1 and 1 by construction. ${ }^{7}$ Balance statistics for expected inflation in all six countries are displayed in Figure 1.

\section{INSERT FiguRE 1 ABOUT HERE}

Since our data are obtained from German forecasters exclusively, one may worry that inflation expectations are very similar for different countries because forecasters focus on Germany and may thus report similar expectations for all countries. As evinced

\footnotetext{
${ }^{7}$ Balance statistics are a common way to aggregate qualitative survey data (see e.g. Pesaran and Weale, 2006). One could use procedures to transform balance statistics into quantitative expectations. However, we do not pursue this here since quantitative expectations are not necessary to test for predictive power but require additional, somewhat arbitrary assumptions in order to be applicable.
} 
by Figure 1 this is definitely not the case. The graphs show that expected inflation can vary substantially for different countries at a given point in time. For example, inflation in Germany and Italy was expected to decrease in the early nineties while inflation was expected to accelerate in the U.K. and U.S.

Descriptive statistics for inflation expectations are shown in Table 1. Panel A reports descriptive statistics for aggregate market returns. Returns follow the usual pattern with low ratios of means to standard deviations, negative skewness and high kurtosis. Panel B reports mean inflation expectations, which are mostly within a one standard deviation interval around zero (except for the U.S.), while the maxima and minima never reach their bounds of plus one and minus one, respectively. Therefore, we do not observe very extreme expectations. The last row $\left(\rho_{-1}\right)$ depicts first-order autocorrelation coefficients which uniformly lie above $90 \%$ in all countries. This indicates a rather high persistence of inflation expectations which seems natural since expectations are six months ahead but are reported on a monthly frequency and thus overlap.

\section{INSERT TABLE 1 ABOUT HERE}

An interesting question is also whether the series of inflation sentiment contains a unit-root or not. We test for this property using augmented Dickey-Fuller (ADF) and Dickey-Fuller GLS tests. Results reported in Table 2 suggest that inflation expectations can indeed be considered as stationary. Apart from this statistical evidence, this result does make sense, since our measure of expected inflation is bound between minus and plus one due to the construction of the balance statistics, so that there is a mechanical tendency towards mean reversion in the long run.

\section{INSERT TABLE 2 ABOUT HERE}

Finally, we relate our inflation sentiment series to inflation expectations from other data sources. This is an interesting issue, since our analysis in the next sections is based on the presumption that German inflation expectations reasonably match 
expected inflation of market participants in the other five countries. To do so, we first investigate whether our inflation sentiment is correlated with data from the U.S., namely data from the Survey of Professional Forecasters (SPF) and the University of Michigan. We employ these series since they are well known in the literature (see e.g. Ang, Bekaert, and Wei, 2007). Specifically, we employ expected inflation for the next two quarters from the SPF and Michigan series to match the forecast horizon of our inflation expectations. ${ }^{8}$ The correlation of our inflation expectations with the Michigan expectations is 0.42 ( $\mathrm{p}$-value for the null of no correlation: 0.00 ) and the correlation with the SPF forecasts is 0.25 (p-value: 0.04). Using other transformations of the data, e.g. using changes or dummy variables that indicate rising or decreasing inflation expectations, yield similar results. Therefore, our data seem to be a reasonable proxy for expectations on U.S. inflation.

Furthermore, we compare our proxies of inflation expectations to similar series derived from Consensus Economics. These data are collected on a monthly basis by Consensus Economics and refer to forecasts from professional institutions (e.g. Banks, research institutes etc.) across major countries in the world. The Consensus data for different forecast horizons depend on the particular date of the forecast. Forecasts are made for the annual inflation rate at the end of the current year, i.e. at the end of January, for instance, the forecast horizon is eleven months ahead while at the end of November the forecast horizon is one month ahead. However, the forecast horizon is about six months on average so that it may still be useful to relate these forecasts to our series. ${ }^{9}$ As with the U.S. data above, we find significant correlations of our inflation sentiment with the Consensus inflation expectations for Germany (0.41, p-value 0.00), the U.S. (0.21, p-value 0.00), France (0.18, p-value 0.01), and Japan (0.20, p-value 0.00). However, we find little evidence for the U.K. where the correlation is 0.09 and insignificant.

All in all, one cannot expect the different proxies for inflation to be perfectly cor-

\footnotetext{
${ }^{8}$ We employ quarterly data here, since the U.S. series are not available on a monthly frequency, and use the last available observation of a given quarter from our monthly series to convert them into a quarterly series.

${ }^{9}$ Since the Consensus forecast series for the inflation rate are found to be non-stationary, we transform the series accordingly by first-differencing.
} 
related due to different data collection schemes and different forecasting horizons. Despite these complications, we find our inflation expectations to represent a reasonable proxy for international inflation expectations on average.

However, for our test below, we choose to employ the ZEW survey series instead of the SPF or Consensus Economics data for two major reasons. First, as noted in the preceding section, we will need comprehensive data that jointly cover expectations regarding output, inflation, and stock returns from the same forecasters in order to discriminate between competing hypotheses that aim at explaining the inflationreturn relation. These data are generally not available from other sources, such as the SPF or Michigan surveys (at least not for a sufficient time span and for a large set of forecasters). Second, data sources that offer all three sets of expectations, such as the Consensus series, are made up by official forecasts of institutions and companies rather than true expectations of individuals. Hence, in order to study a phenomenon such as money illusion (which is inherently linked to the behavior and expectations of individual agents) the ZEW series are more suitable.

Equipped with this confidence of the representativeness of our expectations data, we will now proceed to test whether our proxies for expected inflation have an informational content for subsequent aggregate stock returns.

\section{The Predictive Power of Expected Inflation for Stock Returns}

We run predictive regressions of future returns on expected inflation and other candidate state variables to test the main implications of the proxy hypothesis and money illusion: future real returns should be positively correlated with current expectations about the future path of inflation. In the following (section 4.1), we will first describe the type of regressions employed and how we will deal with persistent regressor biases (Stambaugh, 1999). We will then present our results for in-sample (section 4.2) and out-of-sample predictability (section 4.3).

\subsection{Econometric Methodology}


Our in-sample regressions for a given forecasting horizon $k$ are of the standard form

$$
r_{t+k}=\alpha+\beta_{\pi} \pi_{t}^{e}+\gamma^{\prime} z_{t}+\xi_{t+k}
$$

where $r_{t+k}=(1 / k) \sum_{\ell=1}^{k} r_{t+\ell}$ is the average real log return from time $t+1$ to $t+k$. We denote subjective inflation expectations by $\pi^{e}$ and $z$ is a vector of control variables known to be related to stock returns ( $\gamma$ is a suitably sized column vector of regression coefficients). Specifically, for each of the six countries, $z$ includes the dividend yield, term spread, monthly inflation rate, and the monthly growth of money balances (M2). ${ }^{10}$ The dividend yield and the term spread may be seen as the most important variables, since they are known to have significant predictive power for returns (see Cochrane, 2005, for a discussion). We also include actual inflation (monthly CPI log changes) and M2 growth to control for general monetary factors. ${ }^{11}$ In particular, our focus lies in the estimate and statistical significance of $\beta_{\pi}$ which measures the forecasting power of our survey-based measure of inflation expectations for future returns.

Our main point on predictability will be made by estimating Equation (4) separately for the six countries in our sample. However, in order to increase the power of our tests, we will also present results for pooled system estimators of the form:

$$
\mathbf{r}_{t+k}=\mu_{\mathbf{r}}+\beta_{\pi} \boldsymbol{\Pi}_{\mathbf{t}}^{\mathbf{e}}+\boldsymbol{\Gamma} \operatorname{vec}\left(\mathbf{Z}_{t}\right)+\eta_{t+k}
$$

for different forecast horizons $k^{12}$ In these pooled regressions, $\mathbf{r}_{t+k}$ is a $(n \times 1)$ vector of average real market returns, i.e. we simultaneously employ $n$ out of the six countries. $Z$ now is a $(h \times n)$ matrix of predetermined control variables as detailed above, $\boldsymbol{\Gamma}$ is a matrix of regression coefficients, where the $j^{\text {th }}$ row, $j=1, \ldots, n$, is given by $\left[\begin{array}{llll}\mathbf{0}_{1 \times(j-1) h} & \Gamma_{j} & \mathbf{0}_{1 \times(n-j) h}\end{array}\right]$ with $\Gamma_{j}$ being a $1 \times h$ vector. Furthermore $\Pi^{e}$

\footnotetext{
${ }^{10}$ Using e.g. quarterly instead of monthly growth rates for inflation and M2 is not relevant for the results documented below.

${ }^{11}$ All additional control variables in $z$ are downloaded from Datastream.

${ }^{12}$ Ang and Bekaert (2007) also use pooled regressions to increase the power of tests.
} 
is a $(n \times 1)$ vector of expected inflation in a particular country, while $\beta_{\pi}$ is still a scalar coefficient. Therefore, each country's market return is regressed on a constant, its own lagged control variables in $Z$, and its own lagged expected inflation in $\Pi$. Regression intercepts $\left(\mu_{\mathbf{r}}\right)$ and parameters for the control variables $(\boldsymbol{\Gamma})$ are allowed to vary across countries, whereas the coefficient on expected inflation $\left(\beta_{\pi}\right)$ is restricted to being equal across countries.

Finally, in order to render the impact of inflation sentiment more easily interpretable, we standardize the predictor variable, so that estimated coefficients show the impact of a one standard deviation rise in expected inflation on future stock returns.

It is well-known (Stambaugh, 1999; Valkanov, 2003) that predictive regressions with persistent right-hand side variables, as employed here, may suffer from biased estimates due to the correlation of innovations to returns and regressors. ${ }^{13}$ Thus, regressors are predetermined but not strictly exogenous, which implies that estimates are consistent but not necessarily unbiased. Simulations and analytical results suggest that this bias might be substantial in finite samples of the size typically encountered in empirical studies. Furthermore, using overlapping returns naturally induces a moving average structure of order $k-1$ to the residuals which further complicates inference. Therefore, we employ a parametric bootstrap to account for this finitesample bias and to simulate critical values for our test statistics (see e.g. Kilian, 1999; Mark, 1995; Rapach, Wohar, and Rangvid, 2005, for similar approaches).

Due to these econometric problems, all tables report (a) raw coefficient estimates and t-statistics based on regressions estimated via OLS with Newey-West standard errors with a lag length of $k-1$, and (b) bias-adjusted coefficient estimates and test statistics obtained by bootstrap methods. The bootstrap is based on estimating autoregressive models for all time-series of a given regression. Residuals are bootstrapped and the estimated parameters are used to simulate 10,000 new time-series

\footnotetext{
${ }^{13}$ Moreover, typical predictors such as the dividend yield and macro variables such as the outputprice ratio by Rangvid (2006) or the cay variable by Lettau and Ludvigson (2001) are calculated using market prices. Thus, a potential concern is that the empirically documented predictability may simply result from a temporary "fad" in stock prices being "washed away" (Cochrane, 2007, p.10). This issue does not arise here, however, since expected inflation does not involve scaling by market prices.
} 
under the null of no predictability of length $100+T$, where $T$ is the length of the sample (190 observations). The first 100 simulated observations of all variables involved are discarded. We then estimate the regression models discussed above on the 10,000 simulated time-series, which yields a bootstrap distribution of coefficient estimates and t-statistics. Based on these simulations, we present bias-adjusted coefficients, i.e. the unadjusted coefficient estimate minus the average estimate from the simulations. We also report bootstrap t-statistics, i.e. the bias-adjusted coefficient divided by the standard deviation of the simulated coefficient estimates, and a bootstrap p-value, which is based on the share of simulated t-statistics that are larger (in absolute value) than the absolute value of the raw t-statistic. ${ }^{14}$

We will draw our inference from the bias-adjusted statistics and bootstrap tests. However, we also report raw coefficient estimates and t-statistics as noted above. This is for the sake of completeness and also serves to show that results of our biasadjustments are similar to but much more conservative than unadjusted estimates.

\subsection{Results for In-sample Predictive Regressions}

This section reports results from in-sample predictive regressions of the form shown in (4). We regress six months average real log returns on lagged expected inflation and further lagged control variables, as noted above. Panel A of Table 3, shows the results for the univariate case (expected inflation as the only predictor), whereas Panel B depicts multivariate forecasting regressions with additional control variables as noted above.

As can be seen from the bias-adjusted coefficients in Panel A, expected inflation has a positive coefficient in all countries except Japan and is statistically significant in Germany, the U.S., Italy, and in France. Also, the results are economically significant. Averaged across countries, coefficient estimates imply that a one standard deviation rise in expected inflation raises average monthly returns by about $0.5 \%$ p.m. over the following six months. The effect is most pronounced for France, where

\footnotetext{
${ }^{14}$ We have experimented with other bootstrap procedures, e.g. block bootstraps with different block-selection procedures, and other parametric bootstraps. The results reported in the following are rather similar when employing these alternative bootstrap methods.
} 
a one standard deviation increase of inflation sentiment raises expected returns by about $0.96 \times 6 \approx 6 \%$ over the subsequent six months. The economic effect can also be seen by the rather large adjusted $R^{2}$ s $\left(\bar{R}^{2}\right)$ reported in the Table which displays values as high as $18 \%$ for France. Although $R^{2}$ 's of this size do not seem to be high at first sight, other predictive variables usually perform much worse for stock markets (see e.g. Lettau and Ludvigson, 2001). It is also worth looking at the percentage of adjusted $R^{2}$ s of all bootstrap simulations exceeding the regression $\bar{R}^{2}$, which we denote by $\%\left[\bar{R}_{b}^{2}>\bar{R}^{2}\right]$. These serve as an indicator of possible spuriousness. However, these " $\bar{R}^{2}$-p-values" are rather low and only exceed the $10 \%$ level for the U.K. and Japan, which indicates that our results are not driven by persistent regressor effects.

Panel B of Table 3 shows predictive regressions with additional control variables. Results are similar to those of Panel A, but the impact of expected inflation is even more pronounced. All countries except Japan show a significant relation between expected inflation and future returns and these relations are large from an economic perspective. Again, in order to gauge the significant predictive power of expected inflation, we report incremental $\bar{R}^{2}$ 's $\left(\Delta \bar{R}^{2}\right)$, i.e. the rise in the adjusted $R^{2}$ when additionally including expected inflation in the regressions. Disregarding Japan, these incremental $R^{2}$ 's are high with the lowest value being $10 \%$ and also do not seem to be spurious since the proportion of simulated incremental $R^{2}$ 's generally falls below $10 \%$.

\section{INSERT TABLE 3 ABOUT HERE}

Therefore, the only country which does not show significant effects of expected inflation on returns is Japan. This does not seem to be overly surprising since Japan suffered from a low inflation or even deflation scenario during most of our sample period. Since our forecasters are asked to predict changes in inflation (and not levels), the absence of an effect of expected inflation on returns in such a low inflation environment seems comprehensible. With a Japanese inflation rate of about $0.15 \%$ p.a., as in our sample, expected inflation changes should not have dramatic effects both under the rational account or the money illusion hypothesis in this 
country. The other five countries experienced much higher inflation rates of about 2-3\% p.a., so that changes in expected inflation should have much more pronounced effects than in Japan.

Furthermore, estimates of the pooled model in (5) for three sets of countries are provided in Table 4. Here, we also present results for different forecasting horizons, namely $k=1,3,6,9,12$. Panel A shows the results for pooling all countries. The bias-adjusted coefficient estimate of $\beta_{\pi}$ is strictly positive for all forecast horizons and significantly different from zero for horizons of three to twelve months. Notably, the predictive power, as judged by the bootstrap p-values and the magnitude of the coefficient estimates, does not monotonically increase with the forecasting horizon $k$ but rather peaks at the six months horizon. This result is comforting, since spurious results due to persistent regressors and overlapping observations would simply be increasing in $k$ (see e.g. Hong, Torous, and Valkanov, 2007). Moreover, inflation expectations show their largest predictive power at the horizon at which the survey questions are tailored, which is also a reassuring fact. The size of the estimated coefficient at the six months horizons implies that a one standard deviation shock to expected inflation leads to a more than $3 \%$ increase in real returns over the following two quarters.

The remainder of Table 4 presents estimates when pooling only the continental European countries (Germany, France, Italy - Panel B) or only the Anglo-Saxon countries (U.K., U.S. - Panel C). This grouping is interesting since Germany, France, and Italy are members of the European Monetary Union and may thus be expected to have converging inflation dynamics over our sample. This renders these countries inherently similar for the purpose of our analysis. Furthermore, it is commonly accepted that the Anglo-Saxon countries are similar in terms of their banking and financial system structure and that they have a more capital market based culture (e.g. in terms of pension systems) than the three continental European countries. Therefore, pooling countries along these dimensions yields somewhat homogenous groups but still provides more powerful tests compared to the single country analysis in Table 3. 
Results are similar in the sense that the predictive power of expected inflation shows up at several horizons and that it tends to reach its peak at the six months horizon. The main difference in results is the estimated magnitude of the effects which are stronger for the Continental European countries with a six months effect of almost $5 \%(6 \times 0.79)$ versus a six months effect of about $3.5 \%(6 \times 0.58)$ for the pooled U.K. and U.S. sample. ${ }^{15}$

So far, we can infer that expected inflation carries significant information for future stock returns over multiple horizons and that this forecasting power does not vanish even when we control for other popular forecasting variables such as the dividend yield and the term spread. In the following section, we also examine whether expected inflation is a good predictor for stock returns from an out-of-sample perspective as well.

\section{INSERT TABLE 4 ABOUT HERE}

\subsection{Predictive Power Out-of-Sample}

Contrary to conventional wisdom, in-sample tests might be a more reliable and powerful device to detect predictability than out-of-sample tests (Inoue and Kilian, 2004), since the latter require the full sample to be split up into shorter sub-samples. Nevertheless, confirmative results from out-of-sample (OOS) tests would be comforting and we will provide such results in the following. ${ }^{16}$

\footnotetext{
${ }^{15}$ Of course, one may also consider simple predictive regressions without overlapping observations by throwing away some information. We present such regressions for six-months horizon in Appendix 1. Here, we only use expected inflation from the months of December and June to forecast subsequent six-months real stock returns and we do not include additional control variables. We present individual and pooled estimates. Results are very similar and also show high in-sample $R^{2}$ s, but since the number of observations (32 observations per country) is low, tests have little power so that it is hard to control for other predictor variables.

${ }^{16}$ Recently, there has been a fierce debate in the literature as to the possibility of predicting stock returns out-of-sample. After an extensive analysis of return predictability for the U.S. stock market, Goyal and Welch (2006) question the existence of stock return predictability based on their findings of generally poor OOS performance relative to a naïve benchmark. The papers by Campbell and Thompson (2007) and Cochrane (2006), however, take a different stance on return predictability and provide different interpretations of Goyal and Welch's OOS findings.
} 
Our analysis of OOS predictability is based on a recursive design using the first 5 years as initialization period. Afterwards, the forecasting model is estimated recursively and a $T-R-k-1$ series of (pseudo-) OOS forecasts is generated, where $T$ denotes the overall sample size, $R=60$ is the initialization period, and $k=6$ is the forecast horizon. The performance of forecasts based on inflation sentiment are then compared to those of a naïve (unconditional) benchmark model, which is based on the historical mean of the real stock return known at the date of the forecast (random walk with drift).

Our evaluation of OOS predictability is based on several different tests. First, we report the mean forecast error (ME) and its corresponding t-statistic (based on a HAC-consistent standard error), which can be used to test the unbiasedness of the forecasts. In addition, Theil's $\mathrm{U}$ is displayed, which is computed as the ratio of the root-mean-square error (RMSE) of the model-based forecast and the RMSE of the naïve benchmark model (which is, as usual, a random walk with drift).

In order to test whether the model-based forecasts are superior to the benchmark, we use the recent test by Clark and West (2007) which is designed to compare a parsimonious benchmark model with a larger model which nests the benchmark model. ${ }^{17}$ The t-statistic (provided below MSPE-adj in Table 5) can be used to assess whether the difference between the mean square prediction error (MSPE) of the restricted benchmark model and the adjusted MSPE of the larger model statistically differs from zero (one-sided test). Again, we use a bootstrap approach (moving block bootstrap) to obtain the HAC-consistent standard error. As a final statistic we report the out-of-sample $R^{2}$ following the paper by Campbell and Thompson $(2007) \cdot{ }^{18}$

\footnotetext{
${ }^{17}$ The central idea of the test by Clark and West (2007) is to adjust the mean squared forecast error of the larger unrestricted model for upward bias. The reason is that - under the null hypothesis (additional regressors in the larger model are not necessary for forecasting) - the unrestricted model needs to estimate parameters that are zero in population, which introduces noise in the forecast.

${ }^{18}$ The out-of-sample $R^{2}$ is computed as

$$
R_{O O S}^{2}=1-\frac{\sum_{t=R}^{T-k}\left(r_{t+k}-\hat{r}_{t+k}\right)^{2}}{\sum_{t=R}^{T-k}\left(r_{t+k}-\bar{r}_{t+k}\right)^{2}}
$$

where $\hat{r}_{t+k}$ denotes the return forecast using information on expected inflation as of $t$ and $\bar{r}_{t+k}$ denotes the historical mean return, also computed using data up to $t$.
} 
Table 5 provides OOS forecast evaluation results. The forecasts generally appear to be unbiased and produce lower root-mean-square prediction errors than the naïve benchmark model (Theil's $U$ is smaller than one), which is quite remarkable given the fact that stock returns are notoriously difficult to predict (see Rapach, Wohar, and Rangvid (2005) for a discussion of return predictability with macro variables). The only exception is Japan, consistent with the in-sample estimation results. In three cases (Germany, Italy, France), we find statistical evidence for a superior predictive ability compared to the benchmark model. For these countries, the Clark-West statistic in Table 5 is significant at less than the $10 \%$ level. The results on the out-of-sample $R^{2}$ for Germany, U.K., U.S., and Italy (ranging from 0.02 to 0.07 ) are quite high for a semi-annual horizon, which is (quantitatively) in line with recent results reported by Cooper and Priestley (2006). The OOS $R^{2}$ of $10 \%$ in the case of France points towards a high degree of out-of-sample return predictability by inflation expectations in this country.

\section{INSERT FIGURE 2 ABOUT HERE}

We also investigate the time-variation of OOS performance using Net-SSE plots as in Goyal and Welch (2006), which are a simple but rather informative diagnostic device for comparing the relative OOS performance of competing models over time. ${ }^{19}$ These diagnostic graphs are provided in Figure 2. The Net-SSE plots broadly corroborate the results for Theil's U in Table 5: With the exception of Japan, Net-SSE remains positive at the end of the sample. They also point towards a particularly good OOS performance of models based on inflation sentiment in particular since mid-2001 (especially in the case of Italy and France).

\footnotetext{
${ }^{19}$ Goyal and Welch suggest to plot the cumulative sum of squared forecast errors of the benchmark model minus the squared errors of the conditional model. When the graph exceeds the zero horizontal line, it indicates that the model of interest outperforms the benchmark model in terms of squared forecast errors up to this particular point in time.
} 


\section{Discriminating between Competing Explanations}

We have demonstrated that expected inflation is a strong predictor of stock returns. The empirical approach in this section now seeks to discriminate between the competing hypotheses discussed in section 2. To this end, we perform the following steps. First, we show that the forecasting power of expected inflation is not eliminated when controlling for expected output movements. In the spirit of the pure proxy hypothesis (Fama, 1981), one could argue that inflation expectations proxy for expected real output movements. We show that controlling for such output expectations does not change our main result. Second, we have to discriminate between expected inflation as a proxy for expected aggregate risk aversion and money illusion, which constitutes a challenging task (Campbell and Vuolteenaho, 2004).

However, the risk aversion account makes a clear prediction: If there is a link between inflation and risk aversion, higher subjective inflation expectations should also be associated with higher subjective stock return expectations. This follows from the mechanics of rational expectations which have to be consistent with the underlying economic mechanism. Under money illusion, higher subjective inflation expectations should not be positively correlated with higher subjective stock return expectations since investors are illusioned by the implications of inflation. Rather, as we have argued in section 2, one would expect to observe no or even a negative correlation under this form of investor irrationality. We test these different predictions with a comprehensive set of expectations data, which avoids imposing models and joint hypotheses problems as noted in the introduction.

Consider the pure proxy hypothesis first. If inflation expectations were to proxy for output movements, the predictive power of expected inflation should be erased once we control for output expectations in the predictive regressions. Since our data set also contains subjective expectations about future output movements, we employ a balance statistic similar to the one employed for inflation expectations to proxy for expected output growth. ${ }^{20}$ We then regress future stock returns on expected

\footnotetext{
${ }^{20}$ We subtract the share of forecasters who vote "economic slowdown" from the share of forecasters who vote "economic performance increases". Some descriptive statistics for this economic sentiment
} 
inflation $\pi^{e}$, expected output movements $y^{e}$, and further control variables as before (dividend yields etc.). Results of these regressions are shown in Table 6 which reports bias-adjusted coefficient estimates for a horizon of six months for expected inflation $\left(\beta_{\pi}\right)$ and expected output growth $\left(\beta_{y}\right)$. Furthermore, incremental adjusted $R^{2}$ s for expected inflation (denoted $\triangle \bar{R}^{2}(\pi)$ ) are also depicted.

\section{INSERT TABLE 6 ABOUT HERE}

The table shows that expected inflation is informative for future returns even after controlling for expected output. In fact, we observe a significant forecasting power of expected inflation for all countries except Japan, but there is little evidence for predictive power of expected output. Although expected business conditions have a negative sign as in Campbell and Diebold (2005), the only significant coefficient is obtained for France. Therefore, expected inflation as a proxy for expected business conditions is a very unlikely explanation for the inflation-return relation uncovered in this paper.

As noted above, the second step consists of checking whether the positive inflationreturn relation can be reconciled with a rational explanation in which inflation expectations proxy for (time-varying) risk aversion. To do this, we employ subjective stock return expectations $s^{e}$ obtained from the same data source. Descriptive statistics for these return expectations which we also transform into a balance statistic can be found in Appendix 3. As can be gathered from this Appendix, one cannot reject the null of non-stationarity for some of the series.

For our analysis we run vector autoregressions of the form

$$
Z_{t+1}=\mu+\Gamma Z_{t}+\Phi \Xi_{t}+\left(\begin{array}{ccc}
\varphi_{y, y} & 0 & 0 \\
\varphi_{y, \pi} & \varphi_{\pi, \pi} & 0 \\
\varphi_{y, s} & \varphi_{\pi, s} & \varphi_{s, s}
\end{array}\right) \zeta_{t+1}
$$

where $Z_{t}=\left[\triangle y_{t}^{e}, \triangle \pi_{t}^{e}, \triangle s_{t}^{e}\right]^{\prime}$ is a vector of differenced subjective expectations, $\Xi_{t}$ variable can be found in Appendix 2. 
is a vector of predetermined control variables as above, and $\zeta_{t}=\left[\zeta_{t}^{y}, \zeta_{t}^{\pi}, \zeta_{t}^{s}\right]^{\prime}$ is a vector of structural shocks. The identification scheme shown above is identical to a Cholesky factorization with variable ordering $\triangle y^{e}, \triangle \pi^{e}, \triangle s^{e}$. This ordering seems natural from a macro perspective since it assumes that real output movements drive inflation and that stock returns are driven by macroeconomic conditions. We are mainly interested in estimating $\varphi_{\pi, s}$ which shows the direct, contemporaneous impulse-response of expected stock returns $s^{e}$ to innovations in expected inflation $\pi^{e}$. However, we also include expected output movements $y^{e}$ to control for real macroeconomic conditions. ${ }^{21}$

We employ first differences of subjective expectations since stock return expectations show signs of non-stationarity. Therefore, for the following analysis we rely on cumulative impulse-responses which again allow us to trace the effects on levels. ${ }^{22}$

Starting with the direct effects $\varphi_{i, j}$ in the upper part of Table 7 , we observe that the effect of expected output shocks to expected stock returns $\varphi_{y, s}$ is significant and positive in all six countries. This effect is well in line with standard theory which is illustrated by equation (2) in section 2. However, the direct effect of expected inflation on stock returns $\varphi_{\pi, s}$ is not consistent with a rational expectations framework. The effect of innovations to expected inflation on expected stock returns is strictly negative for all six countries but comparatively weak, since results are largely insignificant. Given the strong and positive relation of expected inflation with actual future returns, investors do not seem to be aware of the predictive power of inflation expectations for future returns. However, this negative and statistically weak relation is exactly what one would expect for money-illusioned investors who are not aware of their mistake under the Modigliani-Cohn hypothesis. ${ }^{23}$

\section{INSERT TABLE 7 ABOUT HERE}

\footnotetext{
${ }^{21}$ The results reported in the following are robust to the inclusion or exclusion of $y^{e}$ and to different identification schemes, e.g. ordering $\pi^{e}$ first or ordering $s^{e}$ first. More generally, $s^{e}$ and $\pi^{e}$ are negatively correlated in all countries.

${ }^{22}$ Using levels or changes in the VAR has no qualitative effect on the results. However, given the mild evidence on non-stationarity for our stock return expectations, using changes seems to be more conservative.

${ }^{23}$ Table 7 also contains some diagnostic tests, namely the adj. Portmanteau statistic for residual autocorrelation and a test for (vector) GARCH effects. Results of these tests indicate that residuals do not suffer from autocorrelation or heteroscedasticity.
} 
Likewise, we also present results for six-months cumulative impulse-responses which we denote as $\Theta_{i, j}$, such that $\Theta_{\pi, s}$, for instance, represents the cumulative response of subjective return expectations to expected inflation shocks. Results do not differ much. Incompatible with a rational account, subjective return expectations do not rise significantly after shocks to expected inflation and, again, the majority of impulse-responses is negative. However, expected output is a significant and positive driver of expected inflation which makes sense from a New Keynesian point of view and indicates that the behavior of forecasters in our sample is not unusual for other macroeconomic variables. Table 7 also shows six-months variance decompositions of subjective stock return expectations, where e.g. $V D_{\pi \rightarrow s}^{(6)}$ denotes the share of variance over a six months forecast horizon due to shocks to expected inflation. Consistent with our findings above, expected inflation has little to say about expected stock returns.

\section{Conclusion}

We have shown that a survey-based measure of expected inflation carries significant forecasting power for future stock returns in several major equity markets. This predictive power shows up in our in- and out-of-sample tests and is most pronounced over intermediate horizons of six months. Although earlier studies predominantly failed to find a positive relation between expected inflation and stock returns, which may be due to different measuring approaches, this positive relation is not unexpected. Variants of the proxy hypothesis as well as of the money illusion hypothesis make exactly the same predictions about the relation of expected inflation and returns as those which have been uncovered in this paper.

Therefore, discriminating between competing hypotheses seems to be an interesting task. We do this by using model-free tests based on relations of subjective investor expectations about future output growth, inflation, and stock returns. Our findings suggest that expected inflation neither proxies for future output movements nor for higher risk aversion under a rational account, since subjective expectations are not consistent with these explanations. Rather, our results favor money illusion as the 
main driver of the predictive power of inflation for stock returns.

Going beyond the results documented in this paper, our findings also have more general implications for asset pricing and macroeconomics. First, since we are employing a sample of several countries, our results suggest that money illusion is not limited to the U.S. which was the prime focus of most of the earlier papers (e.g. Campbell and Vuolteenaho, 2004; Cohen, Polk, and Vuolteenaho, 2005). Second, the effects of money illusion seem to be quite influential. Our point estimates imply that a one standard deviation rise of expected inflation depresses stock returns by more than six percent over the following six months. The strength of this effect may be policy-relevant since it interferes with standard monetary policy transmission channels. For example, the Tobin's Q channel of monetary transmission suggests that central banks can raise output by lowering interest rates, which leads to higher stock valuations and thus raises investment activity (see Tobin, 1968; Barro, 1990; Stock and Watson, 2003, for the mechanism, and the predictive power of asset prices for future output, respectively). If this expansive stance of monetary policy also raises inflation expectations, our results suggest that money illusion may weaken or even outweigh Tobin's Q effect as higher inflation sentiment depresses stock prices, raises future capital costs, and thus weakens incentives to invest. However, we leave an analysis of the macroeconomic implications of money illusion to future research. 


\section{References}

Amihud, Y., 1996. Unexpected Inflation and Stock Returns Revisited - Evidence from Israel. Journal of Money, Credit, and Banking 28(1), 22-33.

Ang, A., G. Bekaert, 2007. Stock Return Predictability: Is it There?. Review of Financial Studies 20(3), 651-707.

Ang, A., G. Bekaert, M. Wei, 2007. Do macro variables, asset markets, or surveys forecast inflation better?. Journal of Monetary Economics 54, 1163-1212.

Barnes, M., J. H. Boyd, B. D. Smith, 1999. Inflation and Asset Returns. European Economic Review 43, 737-754.

Barro, R. J., 1990. The Stock Market and Investment. Review of Financial Studies $3(1), 115-131$.

Basak, S., H. Yan, 2005. Equilibrium Asset Prices and Investor Behavior in the Presence of Money Illusion. Working Paper, London Business School.

Boucher, C., 2006. Stock prices-inflation puzzle and the predictability of stock market return. Economics Letters 90, 205-212.

Brandt, M. W., K. Q. Wang, 2003. Time-varying risk aversion and unexpected inflation. Journal of Monetary Economics 50, 1457-1498.

Brunnermeier, M. K., C. Juillard, 2007. Money Illusion and Housing Frenzies. Review of Financial Studies forthcoming.

Campbell, J. Y., S. Thompson, 2007. Predicting the Equity Premium Out of Sample: Can Anything Beat the Historical Average?. NBER, Working Paper No. 11468, forthcoming Review of Financial Studies.

Campbell, J. Y., T. Vuolteenaho, 2004. Inflation Illusion and Stock Prices. The American Economic Review (Papers \& Proceedings) 94, 19-23.

Campbell, S. D., F. X. Diebold, 2005. Stock Return Predictability and expected business conditions. Working paper, University of Pennsylvania. 
Clark, T. E., K. D. West, 2007. Approximately Normal Tests for Equal Predictive Accuracy in Nested Models. Journal of Econometrics 138, 291-311.

Cochrane, J. H., 2005. Asset Pricing (Revised Edition). Princeton University Press, NJ.

Cochrane, J. H., 2006. The Dog That Did Not Bark: A Defense of Return Predictability. Working Paper, University of Chicago, forthcoming Review of Financial Studies.

Cochrane, J. H., 2007. Financial Markets and the Real Economy. in Handbook of the Equity Premium, ed. by R. Mehra. Elsevier pp. 237-325.

Cohen, R., C. Polk, T. Vuolteenaho, 2005. Money illusion in the stock market: The Modigliani-Cohn hypothesis. Quarterly Journal of Economics 120, 639-668.

Cooper, I., R. Priestley, 2006. Time-varying Risk premia and the Output gap. Review of Financial Studies forthcoming.

Fama, E. F., 1981. Stock Returns, Real Activity, Inflation, and Money. The American Economic Review 71, 545-565.

Fama, E. F., G. W. Schwert, 1977. Asset Returns and Inflation. Journal of Financial Economics 5, 115-146.

Fehr, E., J.-R. Tyran, 2001. Does Money Illusion Matter?. The American Economic Review 91(5), 1239-1262.

Fisher, I., 1928. The Money Illusion. Adelphi, New York, NY.

Flannery, M. J., A. A. Protopapadakis, 2002. Macroeconomic Factors Do Influence Aggregate Stock Returns. Review of Financial Studies 15, 751-782.

Gali, J., M. Gertler, D. Lopez-Salido, 2001. European inflation dynamics. European Economic Review 45, 1237-1270.

Giordani, P., P. Soederlind, 2003. Inflation forecast uncertainty. European Economic Review 47, 1037-1059. 
Goyal, A., I. Welch, 2006. A Comprehensive Look at the Empirical Performance of Equity Premium Prediction. forthcoming Review of Financial Studies.

Gultekin, N. B., 1983. Stock Market Returns and Inflation: Evidence from Other Countries. Journal of Finance 38, 49-65.

Hong, H., W. Torous, R. Valkanov, 2007. Do Industries Lead Stock Markets?. Journal of Financial Economics 83, 367-396.

Inoue, A., L. Kilian, 2004. In-sample or Out of Sample Tests of Predictability: Which one should we use?. Econometric Reviews 23(4), 371-402.

Kilian, L., 1999. Exchange rates and monetary fundamentals: what do we learn from long-horizon regressions?. Journal of Applied Econometrics 14(5), 491-510.

Lettau, M., S. Ludvigson, 2001. Consumption, Aggregate Wealth, and Expected Stock Returns. Journal of Finance 56(3), 815-849.

Mark, N. C., 1995. Exchange Rates and Fundamentals: Evidence on Long-Horizon Predictability. The American Economic Review 85(1), 201-218.

Modigliani, F., R. Cohn, 1979. Inflation, Rational Valuation, and the Market. Financial Analysts Journal 35, 24-44.

Pesaran, M. H., M. Weale, 2006. Survey Expectations. in Handbook of Economic Forecasting, ed. by G. Elliott, C. W. Granger, and A. Timmermann. North-Holland vol. 1 chap. 14 , pp. $715-776$.

Pilotte, E. A., 2003. Capital Gains, Dividend Yields, and Expected Inflation. Journal of Finance 58, 447-466.

Rangvid, J., 2006. Output and expected Returns. Journal of Financial Economics $81,595-624$.

Rapach, D. E., M. E. Wohar, J. Rangvid, 2005. Macro variables and international stock return predictability. International Journal of Forecasting 21, 137-166.

Sharpe, S. A., 2002. Reexamining Stock Valuations and Inflation: The Implications of Analysts' Earning forecasts. Review of Economics and Statistics 84, 632-648. 
Stambaugh, R. F., 1999. Predictive Regressions. Journal of Financial Economics 54, $375-421$.

Stock, J. H., M. W. Watson, 2003. Forecasting output and Inflation: The role of Asset Prices. Journal of Economic Literature 151, 788-829.

Tobin, J., 1968. A General Equilibrium Approach to Monetary Theory. Journal of Money, Credit, and Banking 1, 15-29.

Valkanov, R., 2003. Long-Horizon Regressions: Theoretical Results and Applications. Journal of Financial Economics 68, 201-232. 


\section{Tables and Figures}

Figure 1: Survey Measures of Expected Inflation
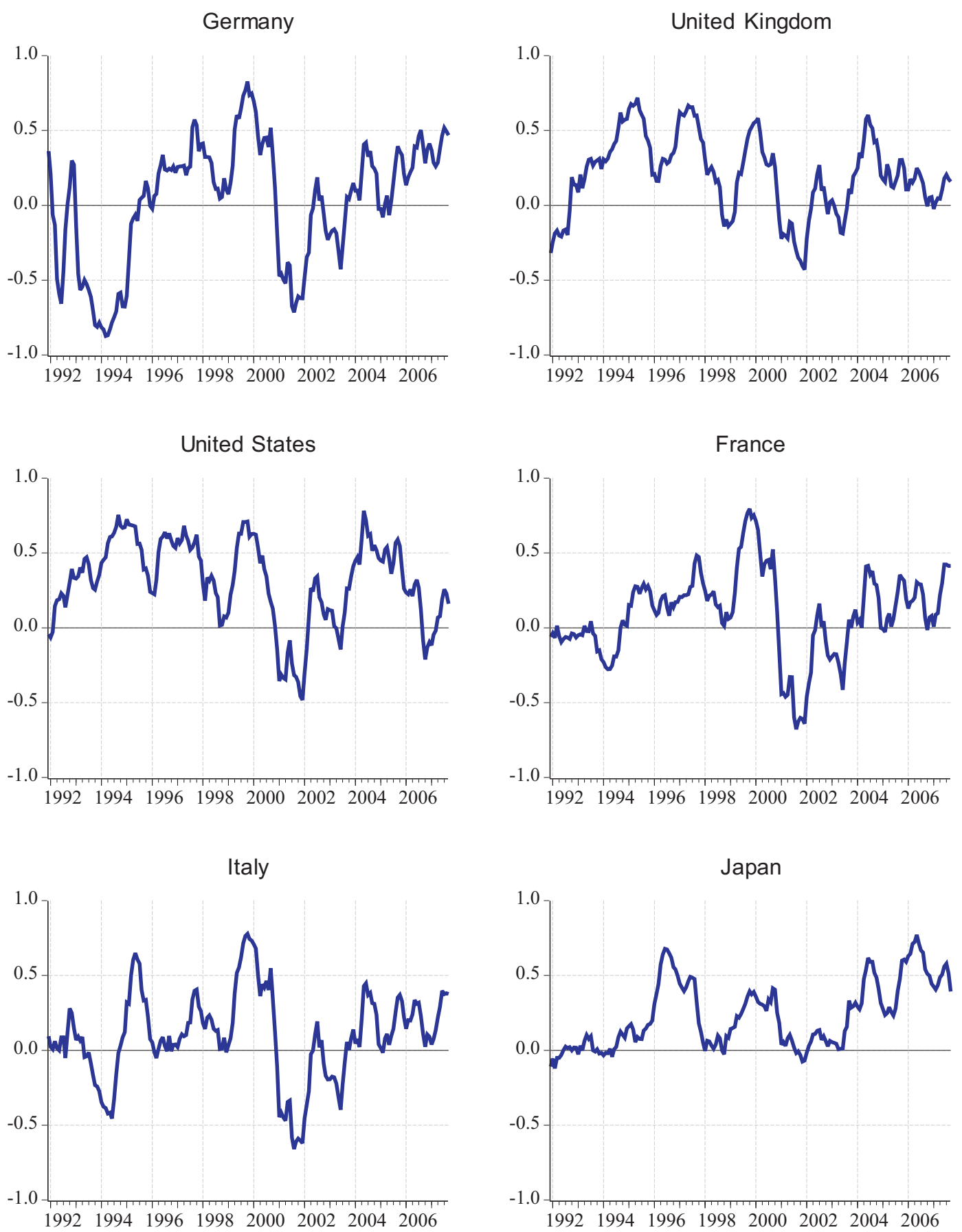

Notes: The figure shows the evolution of expected inflation for the six countries in our sample. The sample range is December 1991 to August 2007. 
Figure 2: Net-SSE Plots

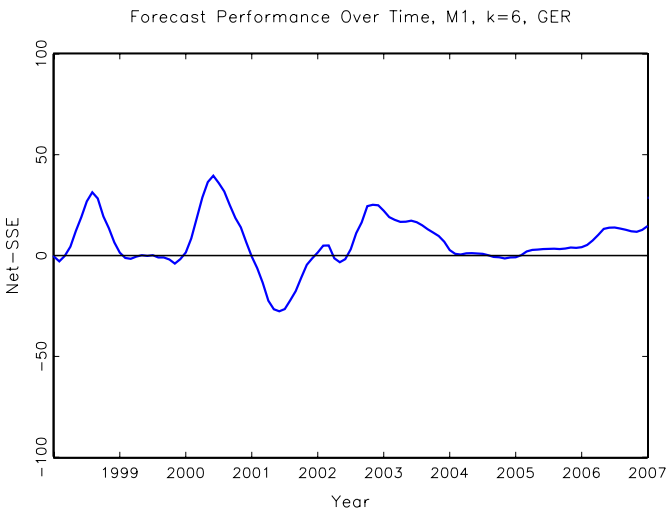

(a) Germany

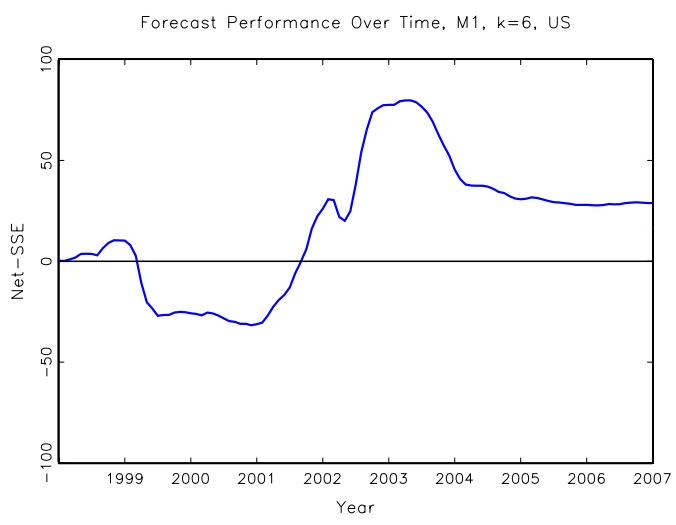

(c) United States

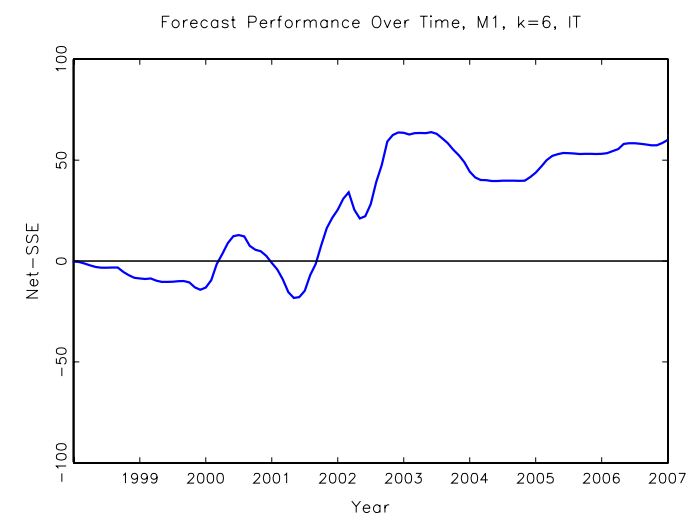

(e) Italy

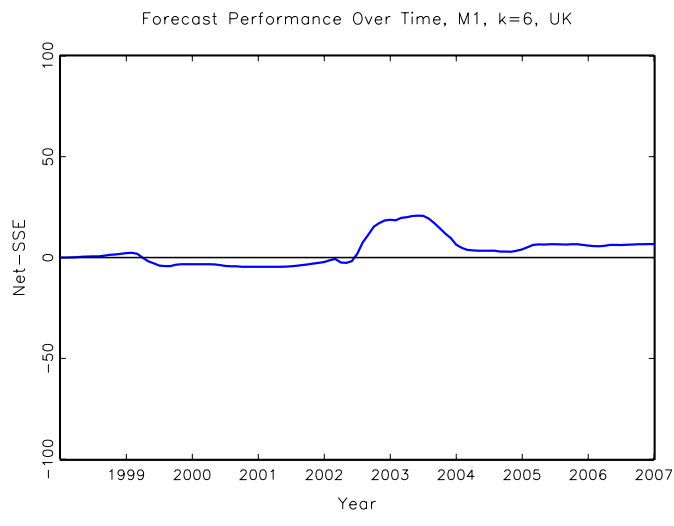

(b) United Kingdom

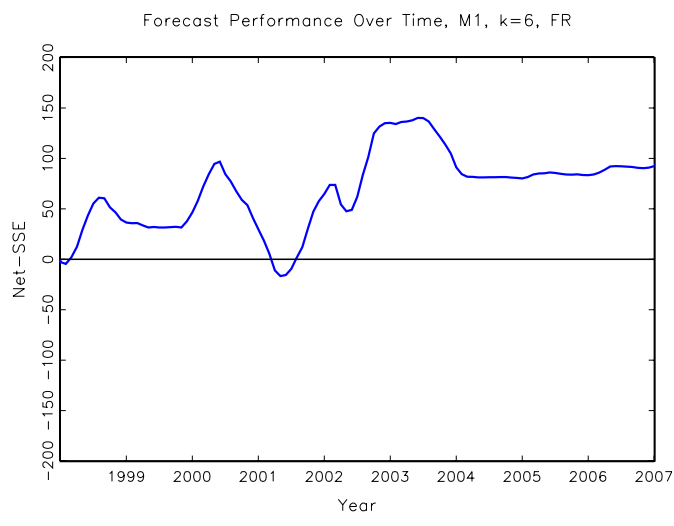

(d) France

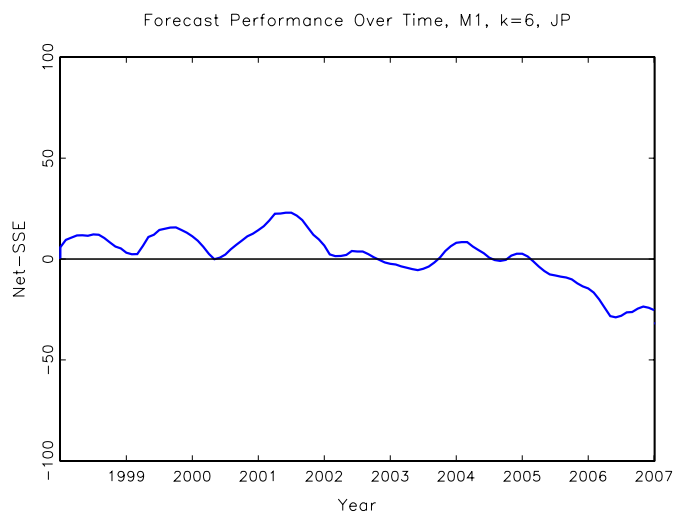

(f) Japan

Notes: The figure shows Net-SSE plots for the aggregate stock market following Goyal and Welch (2006). Net-SSE is the cumulated difference of squared forecast errors of the unconditional benchmark model and the conditional model: $\operatorname{Net-SSE}(\tau)=\sum_{t=1}^{\tau}\left(e_{u c, t}^{2}-e_{c, t}^{2}\right)$, where $e_{u c, t}$ is the forecast error of the unconditional benchmark, and $e_{c, t}$ is the error of the conditional model. A decrease of the slope represents a better forecast performance of the unconditional model at the particular point in time. 
Table 1. Descriptive Statistics

PANel A: Aggregate Stock Market Returns

\begin{tabular}{lrrrrrr}
\hline & GER & U.K. & U.S. & FR & IT & JP \\
\hline Mean & 0.83 & 0.86 & 0.88 & 1.00 & 0.91 & 0.10 \\
SD & 5.38 & 4.05 & 3.83 & 5.29 & 6.26 & 5.20 \\
Skew & -0.86 & -0.75 & -0.51 & -0.52 & 0.15 & 0.17 \\
Kurt & 4.66 & 4.53 & 3.93 & 3.72 & 3.78 & 3.30 \\
Max & 15.00 & 11.62 & 12.45 & 15.26 & 21.14 & 16.46 \\
Min & -20.22 & -14.31 & -11.68 & -16.34 & -17.83 & -13.58 \\
\hline
\end{tabular}

PANEL B: Expected Inflation

\begin{tabular}{lrrrrrr}
\hline & GER & U.K. & U.S. & FR & IT & JP \\
\hline Mean & 0.02 & 0.21 & 0.31 & 0.09 & 0.10 & 0.24 \\
SD & 0.41 & 0.26 & 0.28 & 0.28 & 0.30 & 0.22 \\
Skew & -0.53 & -0.15 & -0.65 & -0.22 & -0.22 & 0.51 \\
Kurt & 2.35 & 2.45 & 2.82 & 3.43 & 3.12 & 2.06 \\
Max & 0.83 & 0.72 & 0.78 & 0.80 & 0.78 & 0.77 \\
Min & -0.87 & -0.43 & -0.48 & -0.68 & -0.66 & -0.12 \\
\hline$\rho_{-1}$ & 0.96 & 0.95 & 0.95 & 0.96 & 0.95 & 0.97 \\
\hline
\end{tabular}

Notes: The table depicts descriptive statistics for aggregate stock market returns (Panel A) and expected inflation (Panel B). SD denotes standard deviation. In Panel A, $\rho_{-1}$ denotes the first order autocorrelation coefficient. 
Table 2. Unit Root Tests

\begin{tabular}{lrrrrrr}
\hline & GER & U.K. & U.S. & FR & IT & JP \\
\hline ADF & -2.88 & -3.01 & -3.13 & -2.88 & -3.02 & -3.21 \\
& $* *(0.05)$ & $* *(0.04)$ & $* *(0.03)$ & $* *(0.05)$ & $* *(0.03)$ & $* *(0.02)$ \\
\multirow{2}{*}{ DF-GLS } & -2.46 & -1.37 & -2.11 & -2.59 & -3.03 & -1.79 \\
& $* *(<0.05)$ & $(>0.10)$ & $* *(<0.05)$ & $* * *(<0.01)$ & $* * *(<0.01)$ & $*(<0.10)$ \\
\hline
\end{tabular}

Notes: The table reports results from Augmented Dickey Fuller (ADF) and DickeyFuller GLS (DF-GLS) unit root tests. Numbers in parentheses are p-values and stars refer to the level of significance: ${ }^{*}: \alpha \leq 0.10,{ }^{* *}: \alpha \leq 0.05$, and ${ }^{* * *}: \alpha \leq 0.01$. 
Table 3. Expected Inflation and Expected Aggregate Stock Returns

PANEL A: Predictive regressions of $r_{t+6}$ on $\pi_{t}^{e}$

\begin{tabular}{lrrrrrr}
\hline & GER & U.K. & U.S. & FR & IT & JP \\
\hline$\beta_{\pi}$ & 0.65 & 0.36 & 0.58 & 0.96 & 0.75 & -0.09 \\
BS t-stat & {$[1.66]$} & {$[1.35]$} & {$[2.12]$} & {$[2.61]$} & {$[1.75]$} & {$[-0.21]$} \\
BS p-val & $*(0.09)$ & $(0.20)$ & $* *(0.04)$ & $* *(0.02)$ & $*(0.09)$ & $(0.73)$ \\
\hline $\bar{R}^{2}$ & 0.07 & 0.04 & 0.13 & 0.18 & 0.08 & 0.00 \\
$\%\left[\bar{R}_{b}^{2}>\bar{R}^{2}\right]$ & 0.09 & 0.18 & 0.02 & 0.00 & 0.08 & 0.78 \\
\hline coef (unadj.) & 0.69 & 0.40 & 0.62 & 0.98 & 0.74 & -0.13 \\
t-stat (unadj.) & 3.92 & 3.06 & 5.38 & 6.30 & 4.00 & -0.69 \\
\hline
\end{tabular}

PANEL B: Predictive regressions of $r_{t+6}$ on $\pi_{t}^{e}, z_{t}$

\begin{tabular}{lrrrrrr}
\hline & GER & U.K. & U.S. & FR & IT & JP \\
\hline$\beta_{\pi}$ & 0.91 & 0.60 & 0.60 & 1.13 & 0.84 & -0.29 \\
BS t-stat & {$[2.15]$} & {$[1.90]$} & {$[1.98]$} & {$[2.78]$} & {$[1.78]$} & {$[-0.67]$} \\
BS p-val & $* *(0.04)$ & $* *(0.03)$ & $* *(0.02)$ & $* * *(0.01)$ & $* *(0.05)$ & $(0.50)$ \\
\hline $\bar{R}^{2}$ & 0.19 & 0.28 & 0.26 & 0.30 & 0.17 & 0.30 \\
$\triangle \bar{R}^{2}$ & 0.12 & 0.11 & 0.12 & 0.22 & 0.10 & 0.01 \\
$\%\left[\triangle \bar{R}_{b}^{2}>\triangle \bar{R}^{2}\right]$ & 0.07 & 0.07 & 0.05 & 0.00 & 0.09 & 0.91 \\
\hline coef (unadj.) & 0.93 & 0.64 & 0.64 & 1.15 & 0.87 & -0.31 \\
t-stat (unadj.) & 3.26 & 3.11 & 3.70 & 3.97 & 3.04 & -1.06 \\
\hline
\end{tabular}

Notes: The first three rows report bias-adjusted coefficient estimates of $\beta_{\pi}$, bootstrap t-statistics, and bootstrap p-values, respectively. $\bar{R}^{2}$ and $\%\left[\bar{R}_{b}^{2}>\bar{R}^{2}\right]$ show adjusted $R^{2}$ s and the share of adj. $R^{2}$ s across simulations that exceed the ordinary $\bar{R}^{2} . \triangle \bar{R}^{2}$ denotes incremental $\bar{R}^{2}$ s, i.e. the rise in the $\bar{R}^{2}$ when additionally including inflation sentiment as a regressor. Rows "coef (unadj.)" and "t-stat (unadj.)" show simple OLS coefficient estimates and t-statistics based on Newey-West HAC standard errors. Stars refer to the level of significance: *: $\alpha \leq 0.10,{ }^{*}: \alpha \leq 0.05$, and $* * *: \quad \alpha \leq 0.01$. 
Table 4. System Estimation Results

\begin{tabular}{lrrrrr}
\multicolumn{6}{c}{ PANEL A: All countries } \\
\hline & $\mathrm{5}=1$ & $\mathrm{k}=3$ & $\mathrm{k}=6$ & $\mathrm{k}=9$ & $\mathrm{k}=12$ \\
\cline { 2 - 6 } & 0.32 & 0.33 & 0.55 & 0.31 & 0.27 \\
\hline$\beta_{\pi}$ & {$[1.10]$} & {$[1.72]$} & {$[2.56]$} & {$[1.49]$} & {$[1.31]$} \\
BS t-stat & $(0.13)$ & $*(0.08)$ & $* * *(0.00)$ & $*(0.06)$ & $*(0.07)$ \\
BS p-val & 0.30 & 0.40 & 0.58 & 0.48 & 0.45 \\
$\beta_{\pi}$ (unadj.) & {$[1.19]$} & {$[1.62]$} & {$[3.51]$} & {$[2.37]$} & {$[2.44]$} \\
t-stat (unadj.) & & & & & \\
\hline
\end{tabular}

PANEL B: GER, FR, IT

\begin{tabular}{lrrrrr}
\hline & \multicolumn{5}{c}{ Forecast horizon (months) } \\
\cline { 2 - 6 } & $\mathrm{k}=1$ & $\mathrm{k}=3$ & $\mathrm{k}=6$ & $\mathrm{k}=9$ & $\mathrm{k}=12$ \\
\hline$\beta_{\pi}$ & 0.57 & 0.80 & 0.79 & 0.54 & 0.29 \\
BS t-stat & {$[1.68]$} & {$[2.48]$} & {$[2.62]$} & {$[1.74]$} & {$[0.93]$} \\
BS p-val & $*(0.07)$ & $* *(0.04)$ & $* * *(0.00)$ & $*(0.07)$ & $(0.20)$ \\
$\beta_{\pi}$ (unadj.) & 0.96 & 0.96 & 1.00 & 0.85 & 0.65 \\
t-stat (unadj.) & {$[2.72]$} & {$[2.20]$} & {$[4.00]$} & {$[2.45]$} & {$[2.06]$} \\
\hline
\end{tabular}

PANEL C: U.K., U.S.

\begin{tabular}{lrrrrr}
\hline & \multicolumn{5}{c}{ Forecast horizon (months) } \\
\cline { 2 - 6 } & $\mathrm{k}=1$ & $\mathrm{k}=3$ & $\mathrm{k}=6$ & $\mathrm{k}=9$ & $\mathrm{k}=12$ \\
\hline$\beta_{\pi}$ & 0.54 & 0.43 & 0.58 & 0.43 & 0.37 \\
BS t-stat & {$[1.86]$} & {$[2.00]$} & {$[2.47]$} & {$[2.00]$} & {$[1.70]$} \\
BS p-val & $* *(0.05)$ & $* *(0.04)$ & $* *(0.01)$ & $* *(0.02)$ & $*(0.06)$ \\
$\beta_{\pi}$ (unadj.) & 0.52 & 0.51 & 0.64 & 0.61 & 0.58 \\
t-stat (unadj.) & {$[2.16]$} & {$[1.91]$} & {$[3.92]$} & {$[2.39]$} & {$[2.29]$} \\
\hline
\end{tabular}

Notes: This table shows system estimation results, where countries are pooled and the coefficient on inflation sentiment is restricted to being the same across countries. The three panels show results for different sets of countries. Stars refer to the level of significance: *: $\alpha \leq 0.10, * *$ : $\alpha \leq 0.05$, and $* * *: \alpha \leq 0.01$. 
Table 5. Out-of-sample Predictive Power

\begin{tabular}{lrrrrrr}
\hline & GER & U.K. & U.S. & FR & IT & JP \\
\hline ME & -0.636 & -0.352 & -0.235 & -0.364 & -0.039 & 0.443 \\
t-stat & $(-1.043)$ & $(-0.816)$ & $(-0.556)$ & $(-0.707)$ & $(-0.067)$ & $(0.663)$ \\
Theil's U & 0.985 & 0.993 & 0.981 & 0.940 & 0.963 & 1.019 \\
MSPE-adj & 0.783 & 0.128 & 0.986 & 3.348 & 0.965 & -0.054 \\
t-stat (CW) & $*(1.421)$ & 0.572 & 0.924 & $* * *(2.234)$ & $*(1.551)$ & -0.196 \\
\hline$R_{\text {OOS }}^{2}$ & 0.030 & 0.013 & 0.037 & 0.116 & 0.073 & -0.038 \\
\hline
\end{tabular}

Notes: The table displays forecast evaluation statistics (forecast horizon of six months). ME denotes the mean prediction error and the t-statistic for testing unbiasedness is provided below. Theil's $U$ is the ratio of the RMSE of the conditional model and the RMSE of the benchmark model. MSPE-adj is the difference of the MSPE of the benchmark model and the adjusted MSPE of the conditional model as in Clark and West (2007); the corresponding t-statistic is reported below. $R_{O O S}^{2}$ denotes the out-of-sample $R^{2}$ as in Campbell and Thompson (2007). *: $\alpha \leq 0.10$, ${ }^{* *}: \alpha \leq 0.05$, and ${ }^{* * *}: \alpha \leq 0.01$ refer to the level of significance in the Clark-West test.

Table 6. Controlling for Economic Sentiment

\begin{tabular}{lrrrrrr}
\hline & GER & U.K. & U.S. & FR & IT & JP \\
\hline$\beta_{\pi}$ & 0.88 & 0.48 & 0.62 & 1.30 & 0.85 & -0.66 \\
BS p-val & $* *(0.05)$ & $* *(0.05)$ & $* *(0.03)$ & $* * *(0.01)$ & $* *(0.05)$ & $(0.19)$ \\
\hline$\beta_{y}$ & -0.07 & -0.51 & -0.79 & -0.80 & 0.05 & 1.15 \\
BS p-val & $(0.82)$ & $(0.12)$ & $(0.11)$ & $* *(0.04)$ & $(0.98)$ & $(0.10)$ \\
\hline $\bar{R}^{2}$ & 0.18 & 0.37 & 0.32 & 0.37 & 0.15 & 0.35 \\
$\triangle \bar{R}^{2}(\pi)$ & 0.12 & 0.09 & 0.07 & 0.27 & 0.10 & 0.04 \\
\hline
\end{tabular}

Notes: $\beta_{\pi}$ denotes the predictive coefficient of expected inflation, whereas $\beta_{y}$ denotes the same statistic for expected output. $\triangle \bar{R}^{2}(\pi)$ is the incremental adjusted $R^{2}$ when including expected inflation as an additional predictor. Stars refer to the level of significance: $*$ : $\alpha \leq 0.10, * *: \alpha \leq 0.05$, and $* * *: \alpha \leq 0.01$. 
Table 7. VAR Analysis

\begin{tabular}{lrrrrrr}
\hline & GER & U.K. & U.S. & FR & IT & JP \\
\hline$\varphi_{y, \pi}$ & -0.005 & 0.007 & 0.012 & 0.010 & 0.010 & 0.024 \\
& $(0.007)$ & $(0.005)$ & $* *(0.005)$ & $*(0.006)$ & $(0.006)$ & $* * *(0.003)$ \\
$\varphi_{y, s}$ & 0.010 & 0.026 & 0.023 & 0.015 & 0.020 & 0.053 \\
& $*(0.006)$ & $* * *(0.005)$ & $* * *(0.006)$ & $* * *(0.005)$ & $* * *(0.006)$ & $* * *(0.006)$ \\
$\varphi_{\pi, s}$ & -0.010 & -0.012 & -0.011 & -0.008 & -0.008 & -0.001 \\
& $*(0.006)$ & $* *(0.005)$ & $*(0.006)$ & $(0.005)$ & $(0.005)$ & $(0.005)$ \\
\hline$\Theta_{y, \pi}^{(6)}$ & 0.033 & 0.046 & 0.050 & 0.060 & 0.050 & 0.064 \\
& $(0.025)$ & $* * *(0.013)$ & $* * *(0.014)$ & $* * *(0.017)$ & $* * *(0.018)$ & $* * *(0.012)$ \\
$\Theta_{y, s}^{(6)}$ & 0.001 & 0.015 & 0.028 & 0.004 & 0.009 & 0.071 \\
& $(0.013)$ & $(0.01)$ & $* *(0.012)$ & $(0.011)$ & $(0.011)$ & $* * *(0.013)$ \\
$\Theta_{\pi, s}^{(6)}$ & -0.016 & -0.017 & -0.016 & 0.004 & -0.007 & 0.013 \\
& $(-0.012)$ & $*(0.09)$ & $(0.011)$ & $(0.010)$ & $(0.010)$ & $(0.012)$ \\
\hline$V D_{y \rightarrow s}^{(6)}$ & 1.81 & 12.74 & 7.52 & 5.42 & 7.30 & 38.30 \\
$V D_{\pi \rightarrow s}^{(6)}$ & 1.89 & 2.87 & 4.54 & 2.43 & 0.99 & 1.30 \\
\hline adj. Q $\mathrm{Q}_{10}$ & 43.88 & 95.41 & 82.17 & 96.75 & 97.44 & 86.35 \\
& $(0.17)$ & $(0.13)$ & $(0.19)$ & $(0.11)$ & $(0.10)$ & $(0.12)$ \\
VARCH$H_{5}$ & 165.95 & 169.20 & 172.88 & 164.90 & 166.42 & 167.28 \\
& $(0.79)$ & $(0.71)$ & $(0.64)$ & $(0.78)$ & $(0.76)$ & $(0.74)$ \\
\hline Lags & 1 & 1 & 2 & 1 & 1 & 2 \\
\hline
\end{tabular}

Notes: $\varphi_{i, j}$ denotes the contemporaneous impact of a shock in variable $i$ on variable $j$, whereas $\Theta_{i, j}^{(6)}$ denotes the six-months cumulative impulse-response of $j$ to shocks in $i$. $V D^{(6)}(i \rightarrow j)$ shows variance decomposition results for a six-months horizon. Numbers in parentheses below $\varphi, \Theta$ are standard errors. Row adj. Q Q $_{10}$ shows the adjusted Portmanteau statistic for serial autocorrelation up to the tenth order and the Lagrange multiplier test statistic for vector ARCH effects with 5 lags is shown in row $\mathrm{VARCH}_{5}$. Numbers in parentheses are p-values. The lag length of the VAR (Lags) is shown in the last row. Stars refer to the level of significance: *: $\alpha \leq 0.10$, **: $\alpha \leq 0.05$, and ***: $\alpha \leq 0.01$. 


\section{Appendix 1. Simple, Semiannual Predictive Regressions}

\begin{tabular}{lrrrrrrr}
\hline & GER & U.K. & U.S. & FR & IT & JP & All \\
\hline const & 5.09 & 3.75 & 1.49 & 4.86 & 5.05 & 4.98 & 5.07 \\
& {$[1.90]$} & {$[1.35]$} & {$[0.45]$} & {$[2.10]$} & {$[1.87]$} & {$[1.30]$} & {$[10.44]$} \\
$\pi^{e}$ & 8.88 & 7.83 & 12.55 & 17.54 & 13.21 & -13.24 & 9.82 \\
& $* *[2.16]$ & {$[1.23]$} & $*[1.87]$ & $* *[2.58]$ & $* *[2.56]$ & {$[-1.62]$} & $* * *[2.62]$ \\
\hline$R^{2}$ & 0.08 & 0.06 & 0.17 & 0.15 & 0.12 & -0.00 & \\
\hline
\end{tabular}

Notes: This table presents predictive regressions for all six countries individually and for pooling all countries (column "All"). The sampling frequency is six months.

\section{Appendix 2. Descriptive Statistics for Economic Sentiment}

\begin{tabular}{lrrrrrr}
\hline & GER & U.K. & U.S. & FR & IT & JP \\
\hline Mean & 0.32 & 0.06 & 0.07 & 0.32 & 0.25 & 0.32 \\
SD & 0.37 & 0.24 & 0.37 & 0.27 & 0.27 & 0.26 \\
Max & 0.90 & 0.61 & 0.85 & 0.80 & 0.80 & 0.80 \\
Min & -0.62 & -0.55 & -0.71 & -0.18 & -0.34 & -0.33 \\
\hline$\rho_{-1}$ & 0.93 & 0.95 & 0.96 & 0.94 & 0.94 & 0.93 \\
\hline ADF & -4.02 & -3.03 & -2.58 & -3.76 & -3.36 & -3.05 \\
& $* * *(0.00)$ & $* *(0.03)$ & $*(0.09)$ & $* * *(0.00)$ & $* *(0.01)$ & $* *(0.03)$ \\
DF-GLS & -1.74 & -2.12 & -1.79 & -2.67 & -2.15 & -1.42 \\
& $*(<0.10)$ & $* *(<0.05)$ & $*(<0.10)$ & $* * *(<0.01)$ & $* *(<0.05)$ & $(>0.10)$ \\
\hline
\end{tabular}

Notes: This table shows descriptive statistics for economic sentiment. SD denotes standard deviation, $\rho_{-1}$ denotes first-order autocorrelations, ADF denotes Augmented Dickey-Fuller test, and DF-GLS denotes Dickey-Fuller GLS tests.

\section{Appendix 3. Descriptive Statistics for Expected Stock Returns}

\begin{tabular}{lrrrrrr}
\hline & GER & U.K. & U.S. & FR & IT & JP \\
\hline Mean & 0.51 & 0.17 & 0.26 & 0.50 & 0.41 & 0.43 \\
SD & 0.13 & 0.28 & 0.21 & 0.13 & 0.17 & 0.19 \\
Max & 0.82 & 0.63 & 0.65 & 0.75 & 0.73 & 0.75 \\
Min & 0.13 & -0.52 & -0.09 & 0.14 & -0.14 & -0.08 \\
\hline$\rho_{-1}$ & 0.80 & 0.93 & 0.95 & 0.81 & 0.88 & 0.89 \\
\hline ADF & -4.55 & -2.73 & -2.42 & -4.41 & -3.60 & -3.53 \\
& $* * *(0.00)$ & $*(0.07)$ & $(0.13)$ & $* * *(0.00)$ & $* * *(0.01)$ & $* * *(0.01)$ \\
DF-GLS & -2.48 & -1.44 & -1.21 & -1.88 & 1.51 & -1.51 \\
& $* *(<0.05)$ & $(>0.10)$ & $(>0.10)$ & $*(<0.10)$ & $(>0.10)$ & $(>0.10)$ \\
\hline
\end{tabular}

Notes: This table depicts descriptive statistics for subjective return expectations. SD denotes standard deviation, $\rho_{-1}$ denotes first-order autocorrelations, ADF denotes Augmented Dickey-Fuller test, and DF-GLS denotes Dickey-Fuller GLS tests. 


\section{SFB 649 Discussion Paper Series 2008}

For a complete list of Discussion Papers published by the SFB 649, please visit http://sfb649. wiwi. hu-berlin.de.

001 "Testing Monotonicity of Pricing Kernels" by Yuri Golubev, Wolfgang Härdle and Roman Timonfeev, January 2008.

002 "Adaptive pointwise estimation in time-inhomogeneous time-series models" by Pavel Cizek, Wolfgang Härdle and Vladimir Spokoiny, January 2008.

003 "The Bayesian Additive Classification Tree Applied to Credit Risk Modelling" by Junni L. Zhang and Wolfgang Härdle, January 2008.

004 "Independent Component Analysis Via Copula Techniques" by Ray-Bing Chen, Meihui Guo, Wolfgang Härdle and Shih-Feng Huang, January 2008.

005 "The Default Risk of Firms Examined with Smooth Support Vector Machines" by Wolfgang Härdle, Yuh-Jye Lee, Dorothea Schäfer and Yi-Ren Yeh, January 2008.

006 "Value-at-Risk and Expected Shortfall when there is long range dependence" by Wolfgang Härdle and J ulius Mungo, Januray 2008.

007 "A Consistent Nonparametric Test for Causality in Quantile" by Kiho Jeong and Wolfgang Härdle, January 2008.

008 "Do Legal Standards Affect Ethical Concerns of Consumers?" by Dirk Engelmann and Dorothea Kübler, January 2008.

009 "Recursive Portfolio Selection with Decision Trees" by Anton Andriyashin, Wolfgang Härdle and Roman Timofeev, January 2008.

010 "Do Public Banks have a Competitive Advantage?" by Astrid Matthey, January 2008.

011 "Don't aim too high: the potential costs of high aspirations" by Astrid Matthey and Nadja Dwenger, January 2008.

012 "Visualizing exploratory factor analysis models" by Sigbert Klinke and Cornelia Wagner, January 2008.

013 "House Prices and Replacement Cost: A Micro-Level Analysis" by Rainer Schulz and Axel Werwatz, January 2008.

014 "Support Vector Regression Based GARCH Model with Application to Forecasting Volatility of Financial Returns" by Shiyi Chen, Kiho Jeong and Wolfgang Härdle, January 2008.

015 "Structural Constant Conditional Correlation" by Enzo Weber, January 2008.

016 "Estimating Investment Equations in Imperfect Capital Markets" by Silke Hüttel, Oliver Mußhoff, Martin Odening and Nataliya Zinych, January 2008.

017 "Adaptive Forecasting of the EURIBOR Swap Term Structure" by Oliver Blaskowitz and Helmut Herwatz, January 2008.

018 "Solving, Estimating and Selecting Nonlinear Dynamic Models without the Curse of Dimensionality" by Viktor Winschel and Markus Krätzig, February 2008.

019 "The Accuracy of Long-term Real Estate Valuations" by Rainer Schulz, Markus Staiber, Martin Wersing and Axel Werwatz, February 2008.

020 "The Impact of International Outsourcing on Labour Market Dynamics in Germany" by Ronald Bachmann and Sebastian Braun, February 2008.

021 "Preferences for Collective versus Individualised Wage Setting" by Tito Boeri and Michael C. Burda, February 2008.

\section{SFB 649, Spandauer Straße 1, D-10178 Berlin} http:/ / sfb649.wiwi.hu-berlin.de

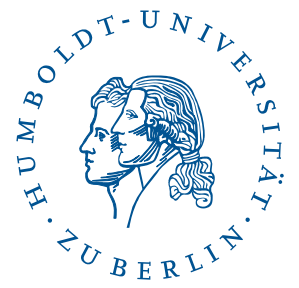


022 "Lumpy Labor Adjustment as a Propagation Mechanism of Business Cycles" by Fang Yao, February 2008.

023 "Family Management, Family Ownership and Downsizing: Evidence from S\&P 500 Firms" by J örn Hendrich Block, February 2008.

024 "Skill Specific Unemployment with Imperfect Substitution of Skills" by Runli Xie, March 2008.

025 "Price Adjustment to News with Uncertain Precision" by Nikolaus Hautsch, Dieter Hess and Christoph Müller, March 2008.

026 "Information and Beliefs in a Repeated Normal-form Game" by Dietmar Fehr, Dorothea Kübler and David Danz, March 2008.

027 "The Stochastic Fluctuation of the Quantile Regression Curve" by Wolfgang Härdle and Song Song, March 2008.

028 "Are stewardship and valuation usefulness compatible or alternative objectives of financial accounting?" by J oachim Gassen, March 2008.

029 "Genetic Codes of Mergers, Post Merger Technology Evolution and Why Mergers Fail" by Alexander Cuntz, April 2008.

030 "Using R, LaTeX and Wiki for an Arabic e-learning platform" by Taleb Ahmad, Wolfgang Härdle, Sigbert Klinke and Shafeeqah Al Awadhi, April 2008.

031 "Beyond the business cycle - factors driving aggregate mortality rates" by Katja Hanewald, April 2008.

032 "Against All Odds? National Sentiment and Wagering on European Football" by Sebastian Braun and Michael Kvasnicka, April 2008.

033 "Are CEOs in Family Firms Paid Like Bureaucrats? Evidence from Bayesian and Frequentist Analyses" by Jörn Hendrich Block, April 2008.

034 "JBendge: An Object-Oriented System for Solving, Estimating and Selecting Nonlinear Dynamic Models" by Viktor Winschel and Markus Krätzig, April 2008.

035 "Stock Picking via Nonsymmetrically Pruned Binary Decision Trees" by Anton Andriyashin, May 2008.

036 "Expected Inflation, Expected Stock Returns, and Money Illusion: What can we learn from Survey Expectations?" by Maik Schmeling and Andreas Schrimpf, May 2008.

SFB 649, Spandauer Straße 1, D-10178 Berlin http:/ / sfb649.wiwi.hu-berlin.de 